\title{
Estimating the Provincial Economic Impacts of Hotels, Scenic Areas and Transportation Infrastructure in China: The Mediating Role of Tourism Development Quality
}

\author{
Liujun Huang \\ Jianquan Guo, Ph.D. \\ University of Shanghai for Science and Technology \\ No.516, Jungong Road, Yangpu District, Shanghai 200093 \\ China
}

\begin{abstract}
Using provincial data of China from 2002 to 2016, this paper conducted structural equation modeling (SEM) with maximum-likelihood estimations focusing upon the effectiveness of tourism development quality as a mediator to explore the impact of hotels, scenic areas and transportation infrastructure on regional economy in China. The results show that hotels, transportation infrastructure and tourism development quality have direct positive effects on regional economy, while scenic areas and transportation infrastructure have indirect positive effects on regional economy via the intermediary of tourism development quality, especially in the case of multi-group analysis in the western region. Other results also show that specific impact of hotels, scenic areas and transportation infrastructure on regional economy is dependent on the development level of different regions.
\end{abstract}

Keywords: Hotels, scenic areas, transportation infrastructure, tourism development quality, regional economy, structural equation modeling, China

\section{Introduction}

China has witnessed rapid inbound and outbound tourism development and star-rated hotel expansion since its accession to the World Trade Organization (WTO) (Shi et al., 2016). In recent years, hospitality industry, which is one of the tourism's three pillars, has developed rapidly (Song, 2016), especially high star-level hotels represented by four and five-star hotels (Zheet al., 2019). It is commonly acknowledged that the high star-rated hotel industry contributes to better job creation, output and business opportunities, thereby yielding higher levels of local tourism and economic growth (Barnabé and Zhang, 2018;Dai et al., 2017).In addition, high star-rated hotels tend to be concentrated in areas with high-end tourism resources (Liu and Zhao, 2013), such as national-level scenic spots and world natural heritage. As an important material carrier of tourism development, national-level scenic spots play an important role in the market economy with unique resource form and product form (Qu, 2004).

Investment in transport infrastructure is considered an important catalyst for development and spatial integration within or between countries ( $\mathrm{Hu}$ and $\mathrm{Zhu}, 2015)$. Better accessibility to resources, goods and markets improves the competitiveness of a region, which then stimulates the production level (Bartlomiej and Marcin, 2018), and induces new economic activities and investment, thus strengthening economic growth and creating more employment opportunities in the region (Shao et al., 2017). Meanwhile, better construction and improvement of transportation infrastructure functions as promoting regional tourism cooperation, jointing development of tourism resources through network effects, improving the quality of tourism products and reducing tourism development cost.

The tourism industry carries significant weight for economy, as it represents one of the main and most important revenue sources, particularly for tourism-enhanced regions. Tourism has become an important strategic tool for destination countries and regions to stimulate economy growth for its perceived ability to generate foreign exchange income, attract international investment, increase tax revenue, promote tourism-related value chain development (Tang and Abosedra, 2014), and alleviate poverty (Zhao et al., 2018; Croes and Rivera, 2016).However, the positive effect of tourism on regional economy is dependent not only on the scale of tourism development in the region, but on the quality of its tourism development (Chen and Huang, 2006; Zhang et al., 2015).

As a multivariate statistical technique, structural equation modeling (SEM) can discover the direct or indirect relationships between exploratory variables and a dependent variable and then visualize the causal influencing pathways and medicating effect (You, 2017). Previous pilot studies have indicated that SEM is suitable for social and economic studies (Deng et al., 2013; Kick and McKinney, 2014). However, few studies have applied SEM to investigate the relationships between hotel, tourism and regional economy development, as well as the mediating factors. 
Most scholars paid attention to the relationship between tourism and regional development by employing structural equation modeling, such as the impact of medical tourism development on community well-being (Courtneyet al., 2018), the satisfaction of border tourism (Juan et al., 2017), the impact of community tourism on sustainable development (Lee and Jan, 2019), residents' support for red tourism in China (Zuo et al., 2017) and so on. Some researchers have also studied the relationship between different factors and regional economic development. Li et al. (2018) analyzed the direct or indirect relationship between road infrastructure in Jiang-Zhe-Hu region (highly developed) and the Yun-Gui-Chuan region (less developed) and the local economy based on SEM model.Jiang et al. (2017) employed SEM model to study the relationship between transportation infrastructure and regional economy. Fan and Wei (2016) studied the impact of GDP and bilateral trade volume on the potential variables of China's economy in the core countries and regions of the Silk Road Economic Belt based on SEM model. In the use of SEM models to study hotel related issues, most researchers have mainly focused on the competitive advantage of hospitality industry (Hew et al., 2018), the determinants of hotel success and development (Yadegaridehkordi et al., 2018), and the link between hotel business strategy and performance (González-Rodríguez et al., 2018). The above research is based on a single research perspective mostly. However, the current research on hotel, tourism and regional economic development from multi-angle systems using SEM models is still rare.

Therefore, this paper constructs a structural equation model (SEM) to explore the impact of hotels, scenic areas and transportation infrastructure on regional economy and the mediating role of tourism development quality in this process. This paper further studied the impact pathways and mechanisms of the above effects in the eastern, central and western regions of China.

The remainder of this paper is structured as follows: Section two presents literature review and hypothesis development; Section three introduces the methodology; Section four presents and discusses the model estimation results and Section five provides a brief summary and conclusions; Limitations and future suggestions are drawn in the last section.

\section{Literature review and hypothesis development}

\subsection{Hotels and tourism, regional economy}

Hospitality industry is one of the forces that cannot be ignored in economic construction (Song, 2016).According to Frank et al. (1994), the hotel industry can create jobs, output and promote regional economic development. Shi et al. (2016) discovered that the expansion of high star-rated hotels in China significantly affected the development of inbound tourism. As illustrated by Jeffrey and Hubbard (1988), the development of inbound tourism and hotel industry increased regional economic benefits. Dai et al. (2017) showed that hotel investment has an economic impact on GDP and employment. High star-rated hotels represent the higher management level and grade of hotels (Zhe et al., 2019). Hence, following several past studies (Shi et al., 2016; Zhe et al., 2019), four and five-star hotels are taken as high starrated hotels to measure the development of the hotel industry in this study. Accordingly, the following hypotheses are developed:

H1. High star-rated hotels have a positive impact on regional economy development.

\subsection{Scenic areas and tourism, regional economy}

With high economic value of tourism, scenic resources play a crucial role in promoting regional economic development (Lin, 2013).According to a review conducted by Cao et al. (2012), when the location accessibility and production factors meet a certain threshold, the location accessibility promotes tourism efficiency in general. As argued by Guo et al. (2017), the cohesive development of scenic spots in Beijing-Tianjin-Hebei, Yangtze River Delta and Pearl River Delta regions is conducive to the economies of scale and external economy of tourism development in the evaluation of locational advantages of national-level scenic spots. Qu (2004) studied the core competitiveness of tourism in key national scenic spots, and confirmed that it should concentrate on limited resources to develop tourism core competitiveness, and thus achieving sustainable development of scenic spots and increasing economic benefits. Operationalized as an important support for the development of China's tourism industry, the national-level scenic spots are the highest-level and most valuable tourist destinations in China's scenic spots system (Yang, 2013). Therefore, the national-level scenic spots are considered an essential tool for measuring the development of scenic areas in this paper. As such, the following hypotheses are offered:

H2. National-level scenic spots have a positive impact on regional economy development.

\subsection{Transportation infrastructure and hotels, scenic areas, tourism, regional economy}

For hotel operations and spatial distribution, the high accessibility of a well-established transportation infrastructure is crucial (Assaf et al., 2015; Liu, 2017). 
Meanwhile, traffic accessibility is considered as one of the driving factors for the location advantage of national scenic spots (Guo et al., 2017).Zhang and Zhao (2018) demonstrated that the traffic infrastructure in the adjacent area has significant positive spillover effects on star-rated hotels, travel agencies and tourist attractions. In the words of Strauss et al. (2018), improved accessibility of transportation can boost GDP, GDP per capita, and employment growth. Khan et al. (2017) confirmed that air transport, rail transport and trade openness have a positive impact on the inbound tourism index.The construction of transportation infrastructure can promote the development of tourism destinations, and its level will affect the scale and quality of regional tourism development (Li and Huang, 2015). As cited in Pradhan and Bagchi (2013), transportation infrastructure can also influence economic growth by changing aggregate demand and stimulating multiplier effects. Hence, the following hypotheses are formed:

H3.Transportation infrastructure has a positive impact on high star-rated hotels.

H4. Transportation infrastructure has a positive impact on national-level scenic spots.

H5. Transportation infrastructure has a positive impact on regional economy development.

\subsection{Tourism development quality and regional economy}

The quality of tourism development is to meet the needs of tourism development and tourism consumption in terms of products, services and environment, and its degree of satisfaction presents an ever-increasing trend of change with significant sustainability (Zhang et al., 2015).Chen and Huang (2006) conducted a comprehensive evaluation of the development quality of China's tourism industry from the aspects of product quality, environmental quality, factor quality, and industrial growth mode, and found that the stability of the economic benefits of the tourism industry is relatively poor. As described by Chen et al. (2014), when the quality of inbound tourism matches the quality of scenic spots, tourism resources can be fully utilized. Similarly, Zhang et al. (2015) indicated that the overall quality of tourism development in the eastern region of China is higher, followed by the central region and the lowest in the west. The next hypothesis is constructed accordingly:

H6. Tourism development quality has impacts on regional economy development.

Based on the above analysis, hotels, scenic areas and transportation infrastructure not only have a direct impact on the regional economy, but also may affect the quality of tourism development, and have an indirect impact on the regional economy through the intermediary role of tourism development quality. Accordingly, the next six hypotheses are developed:

H7. High star-rated hotels have a positive impact on tourism development quality.

H8. National-level scenic spots have a positive impact on tourism development quality.

H9. Transportation infrastructure has a positive impact on tourism development quality.

H10. High star-rated hotels have a positive effect on regional economy development mediated through tourism development quality.

H11. National-level scenic spots have a positive effect on regional economy development mediated through tourism development quality.

H12. Transportation infrastructure has a positive effect on regional economy development mediated through tourism development quality.

The features of the cited papers and gap in the literature are shown in Table 1.

Table 1. Comparing our paper with the cited articles

\begin{tabular}{|c|c|c|c|c|c|c|c|c|}
\hline & $\begin{array}{l}\text { High } \\
\text { star- } \\
\text { rated } \\
\text { hotels }\end{array}$ & $\begin{array}{l}\text { National- } \\
\text { level scenic } \\
\text { spots }\end{array}$ & $\begin{array}{l}\text { Transportation } \\
\text { infrastructure }\end{array}$ & $\begin{array}{c}\text { Tourism } \\
\text { development } \\
\text { quality }\end{array}$ & $\begin{array}{l}\text { Regional } \\
\text { economy }\end{array}$ & SEM & $\begin{array}{c}\text { Mediation } \\
\text { effect }\end{array}$ & $\begin{array}{c}\text { Multi- } \\
\text { group } \\
\text { analysis }\end{array}$ \\
\hline Shi(2016); Dai(2017);Zhe(2019) & $\sqrt{ }$ & & & & & & & \\
\hline $\begin{array}{c}\text { Hew(2018); Yadegaridehkordi } \\
\text { (2018);González-Rodríguez (2018) }\end{array}$ & $\sqrt{ }$ & & & & & $\sqrt{ }$ & $\sqrt{ }$ & \\
\hline Liu(2017);Zhang(2018) & $\sqrt{ }$ & & $\sqrt{ }$ & & & & & $\sqrt{ }$ \\
\hline Courtney(2018);Zuo(2017) & & & & & & $\sqrt{ }$ & $\sqrt{ }$ & \\
\hline Guo(2017); Cao(2012); Qu(2004) & & $\sqrt{ }$ & & & & & & $\sqrt{ }$ \\
\hline Huet al. (2015) & & & $\sqrt{ }$ & & & & & $\sqrt{ }$ \\
\hline $\begin{array}{c}\text { Chen(2006); Zhang et al. } \\
\text { (2015); } \mathrm{Ma}(2009)\end{array}$ & & & & $\sqrt{ }$ & & & & $\sqrt{ }$ \\
\hline Li (2018); Jiang(2017) & & & $\sqrt{ }$ & & $\sqrt{ }$ & $\sqrt{ }$ & $\sqrt{ }$ & $\sqrt{ }$ \\
\hline Our paper & $\sqrt{ }$ & $\sqrt{ }$ & $\sqrt{ }$ & $\sqrt{ }$ & $\sqrt{ }$ & $\sqrt{ }$ & $\sqrt{ }$ & $\sqrt{ }$ \\
\hline
\end{tabular}

\section{Methodology}

\subsection{Statistical analysis and modeling}

Structural equation modelling makes it possible to measure the simultaneous relationships between a set of independent variables and a set of dependent variables, allowing then for the identification of causal relationships between latent 
variables (Juan et al., 2019). The structural equation model (SEM) method was employed to further study the impact of hotels, scenic areas and transportation infrastructure on regional economy in this paper. The advantages of SEM over other statistical models areas follows. Firstly, multiple dependent variables can be considered and processed simultaneously. Secondly, independent variables and dependent variable items are allowed to contain measurement errors. Thirdly, latent variables are usually allowed to be composed of multiple explicit indicator variables, and the reliability and validity of the indicator variables can be estimated at the same time (Sun, 2005). Fourthly, it is possible to study the direct, indirect and total effects among variables, and also, the role of mediators. The direct and indirect impacts of hotels, scenic areas, and transportation infrastructure on the regional economy are hypothesized in this study. Therefore, the SEM method is suitable.

The basic equations of the structural and measurement models are the following (Chenand Silva, 2014). The measurement part of the SEM model is defined as:

$$
y_{i}=v+\Lambda \eta_{i}+\mathrm{K} x_{i}+\varepsilon_{i}
$$

Where $\eta$ is an $\mathrm{m}$-dimensional vector of latent variables, $x$ is a $q$-dimensional vector of covariates, $\varepsilon$ is a $p$-dimensional vector of residuals or measurement errors which are uncorrelated with other variables, $v$ is a $p$-dimensional parameter vector of measurement intercepts, $\Lambda$ is a $\mathrm{p} \times \mathrm{m}$ parameter matrix of measurement slopes orfactor loadings, and Kis a $\mathrm{p} \times \mathrm{q}$ parameter matrix of regression slopes.

The structural part of the model is defined in terms of the latent variables regressed on each other and the qdimensional vector $x$ of independent variables,

$$
\eta_{i}=\alpha+\mathrm{B} \eta_{i}+\Gamma x_{i}+s_{i}
$$

Here, $\alpha$ is an $m$-dimensional parameter vector, $\Gamma$ is an $\mathrm{m} \times \mathrm{q}$ slope parameter matrix for regressions of thelatent variables on the independent variables, Bis an $\mathrm{m} \times \mathrm{m}$ parameter matrix of slopes for regressions of latentvariables on other latent variables, and $\varsigma$ is an $\mathrm{m}$-dimensional vector of residuals.

\subsection{Variable definitions and data sources}

Following the conceptual model, the possible mediating variable is selected (Table 2). In addition, observed indicators are applied to indicate the latent variables (hotels, scenic areas, transportation infrastructure, tourism development quality, regional economy) respectively. Considering the availability of data, we employed the panel data of the provinces and cities in China excepting Tibet. Data sources for the variables between 2002 and 2016 include the China Statistical Yearbook (2001, 2017), the China Urban Construction Statistical Yearbook (2001, 2017), the Yearbook of China Tourism Statistics $(2001,2017)$, the Statistical Yearbook of each province and other ways. The missing portion of the data was processed using the EM estimate of SPSS 19.0. Besides, to ensure the validity of the model estimation and the consistency of variable processing, logarithmic processing was performed on other variables except PHSH and OPEN. The specific variable definitions and data sources are shown in Table 2.

Table 2. List of observed and latent variables

\begin{tabular}{lll}
\hline Latent Variables & Observed Indicators & Abbreviation \\
\hline Hotels (HOTEL) & Number of high star-rated hotels & HSH \\
& The proportion of high-star hotels in star-rated hotels & PHSH \\
Scenic areas (NSS) & Number of National-level scenic spots & NNSS \\
& Number of visits & NTSS \\
& Operational income of National-level scenic spots & OISS \\
Transportation infrastructure (TI) & Railways passenger traffic & PTR \\
& Highway passenger traffic & PTH \\
Tourism development quality (QTD) & Tourist times & NT \\
& Employees of tourism industry & TP \\
& Total travel agencies & TA \\
& Area of nature reserves & NR \\
Regional economy (RE) & Openness & OPEN \\
& GDP per capita & PGDP \\
& Direct foreign investments & FDI \\
& Total energy consumption & EC \\
\hline
\end{tabular}

\subsection{Overall theoretical model test}

The SPSS19.0 software was used to test the reliability of the statistics of hotels, scenic spots, transportation infrastructure and regional economy. The results showed that the Cronbach's Alpha coefficient was 0.880, indicating 
good reliability. Before the empirical results analysis, the performance of the model needs to be evaluated. This study examines the overall model according to the accepted indicators CMIN/DF, RMSEA, NFI, IFI, CFI, PNFI (Najaf et al., 2018). See Table 3 for details.

Table 3. Adaptation index

\begin{tabular}{lllll}
\hline & \multicolumn{2}{l}{ Absolute suitability statistics } & Value-added suitability statistics & Simple adaptation statistics \\
\cline { 2 - 4 } & CMIN/DF & RMSEA & NFI IFI CFI & PCFI PNFI \\
\hline Criterion & $\leq 10$ & The smaller the better & The closer to 1 the better & $\geq 0.5$ \\
\hline
\end{tabular}

AMOS22 was employed to verify the hypothesis model. In order to meet the requirements of the model fitting degree, a two-way connection to the error value with large M.I. value was established. The result is shown in Figure 1. The corrected reliability index is as follows: $\mathrm{CMIN} / \mathrm{DF}=7.789$, RMSEA=0.123, NFI=0.949, IFI=0.956, CFI=0.955, PCFI $=0.642$, PNFI $=0.639$. According to the criteria in Table 3, each fitting index has reached a relatively good level, indicating that the fitting degree is better.

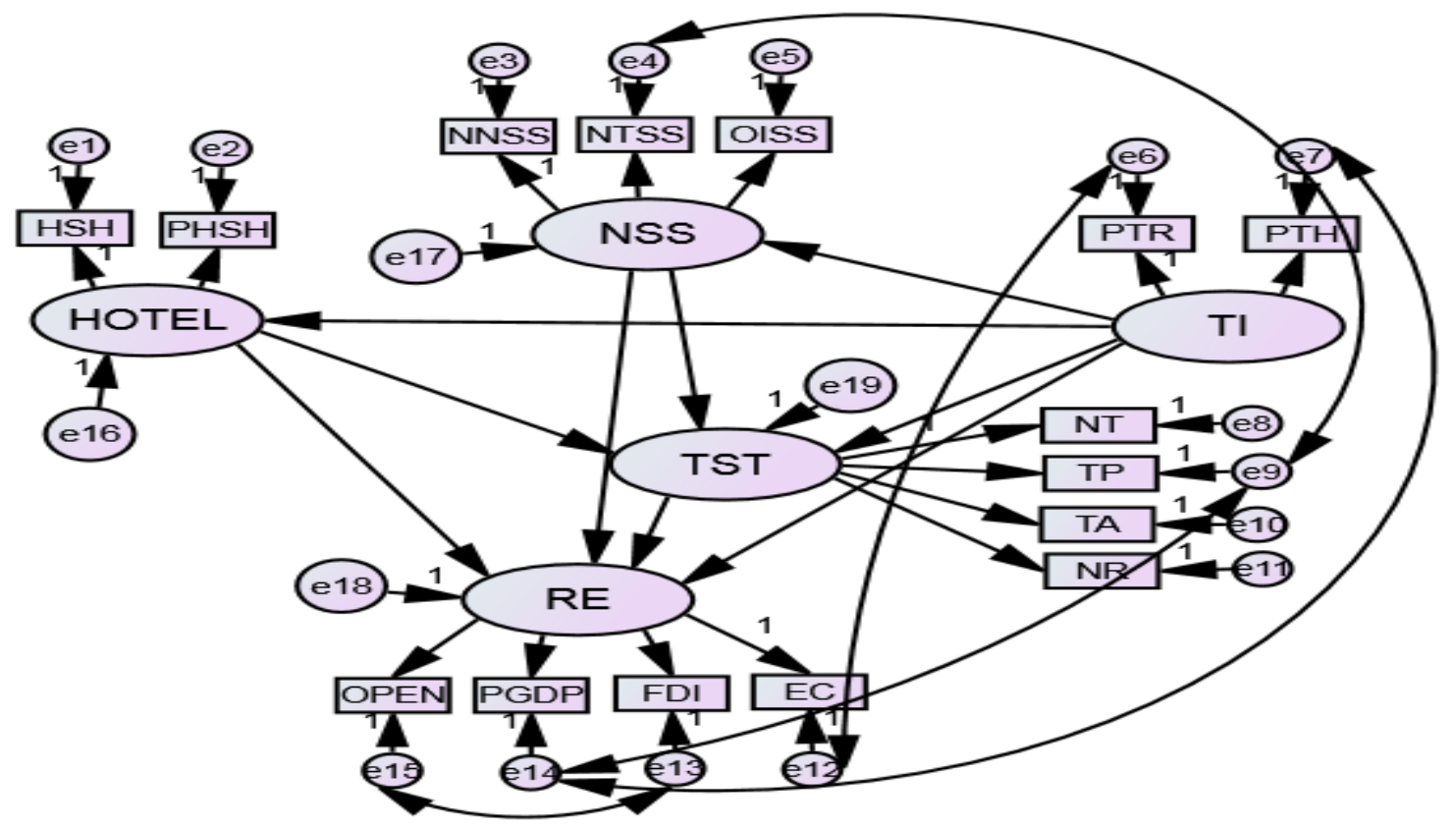

Figure 1. Corrected path of SEM model

\section{Empirical results and discussion}

\subsection{Model performance and path coefficients for overall area}

Based on the statistical significance of the regression coefficient depicted in Table 4, this study finds supports for $\mathrm{H} 1$, H3, H4, H5, H6, H9, H12.

Table 4. Outcome of SEM model

\begin{tabular}{|c|c|c|c|c|c|c|}
\hline Hypotheses & Regression paths & Std. Estimates & $P$-values & S.E. & C.R. & Remarks \\
\hline H1 & RE<--- HOTEL & .199 & $* * *$ & .027 & 7.417 & Supported \\
\hline $\mathrm{H} 2$ & RE<--- NSS & -.617 & $* * *$ & .069 & -8.994 & Unsupported \\
\hline H3 & HOTEL<--- TI & 1.250 & $* * *$ & .083 & 15.112 & Supported \\
\hline $\mathrm{H} 4$ & NSS<--- TI & .490 & $* * *$ & .037 & 13.208 & Supported \\
\hline H5 & RE<--- TI & .135 & $* * *$ & .020 & 6.707 & Supported \\
\hline H6 & RE<--- QTD & .373 & $* * *$ & .033 & 11.365 & Supported \\
\hline H7 & QTD<--- HOTEL & -1.272 & .001 & .388 & -3.281 & Unsupported \\
\hline H8 & QTD<--- NSS & -3.694 & $* * *$ & .714 & -5.174 & Unsupported \\
\hline H9 & QTD<--- TI & 5.338 & $* * *$ & .785 & 6.800 & Supported \\
\hline Hypotheses & Regression paths & Specific indirect effects & Direct effect & Total effect & $\begin{array}{l}\text { Types of } \\
\text { Mediation }\end{array}$ & Remarks \\
\hline H10 & RE<---QTD<--- HOTEL & $-.475 * * *$ & $.199 * * *$ & $-.276 * * *$ & Partial mediation & Unsupported \\
\hline H11 & RE<---QTD<--- NSS & $-1.379 * * *$ & $-.617 * * *$ & $-1.995 * * *$ & Partial mediation & Unsupported \\
\hline $\mathrm{H} 12$ & RE<---QTD<--- TI & $.670 * * *$ & $.135^{* * * *}$ & $.805 * * *$ & Partial mediation & Supported \\
\hline
\end{tabular}

Note: Std. Estimate standardized estimates, S.E. standard error, C.R. critical ratio

$* p<0.05, \quad * * p<0.01, \quad * * * p<0.001$ 
The specific analysis is as follows:

(1) Hypothesis H1 is established. High star-rated hotels have a significant positive effect on the regional economy. With the increase in demand in the tourism market, it has attracted more high-end hotel investment, which meanwhile has promoted the development of regional convention and exhibition industry, business and shopping tourism (Pine, 2005; Sarmento and Simões, 2018), and thus contributing to the development of the regional economy.

(2) Hypothesis $\mathrm{H} 3, \mathrm{H} 4, \mathrm{H} 5, \mathrm{H} 9$ are established. The transportation infrastructure has significantly promoted the development of high star-rated hotels and national-level scenic spots as well as the quality of tourism development and regional economy. Firstly, the accessibility of transportation infrastructure expands the scope of tourism market and industry scale, and promotes the development of tourism service industry (such as high star-rated hotels) and regional economy (Hu, 2016). Secondly, the convenience of the transportation network directly affects the sustainable development of tourism in scenic areas. The superior traffic location can reduce the investment cost of scenic areas and improve economic benefits (Wangand Guo, 2016).

(3) Hypothesis H6, H12 are established. The quality of tourism development has a direct positive effect on the regional economy. Other than exerting a direct impact on regional economy, transportation infrastructure indirectly influences regional economy through tourism development quality. The high-quality tourism environment has become an important component of tourism attractiveness. The improvement of the quality of tourism products, tourism services, tourism markets, tourism facilities, and tourism environment can on the one hand increase economic benefits of tourism industry and regional economy, on the other hand, significantly improve the regional economic effects of transportation infrastructure.

\subsection{Multi-group analysis}

The above analysis shows that hotels, transportation infrastructure and tourism development quality have a direct positive effect on the regional economy excepting scenic spots. Due to the special spatial distribution of scenic resources (Liand Bi, 2016; Zhu and Chen, 2008), the imbalance of regional economic development (Zhouet al., 2002) and the uniqueness of economic development in various regions, the whole sample was divided into three types (the highly developed eastern region, medium developed central region and less developed western region) for multi-group analysis to further explore the relationship between hotels, scenic spots, transportation infrastructure and different development level regional economy in China. The empirical results are shown in Table 5 and Table 6.

Table 5. Grouping results of SEM model

\begin{tabular}{|c|c|c|c|c|c|c|c|c|c|c|}
\hline \multirow{2}{*}{ Hypotheses } & \multirow{2}{*}{$\begin{array}{l}\text { Regression } \\
\text { paths }\end{array}$} & \multicolumn{2}{|c|}{ Eastern region } & \multirow[b]{2}{*}{$\boldsymbol{P}$} & \multicolumn{3}{|c|}{ Central region } & \multicolumn{3}{|c|}{ Western region } \\
\hline & & Estimate & C.R. & & Estimate & C.R. & $P$ & Estimate & C.R. & $\boldsymbol{P}$ \\
\hline H1 & RE<--- HOTEL & .318 & $\begin{array}{l}14.6 \\
22\end{array}$ & $* * *$ & .396 & 4.251 & $* * *$ & .226 & 3.454 & $* * *$ \\
\hline $\mathrm{H} 2$ & RE<--- NSS & -.374 & $\begin{array}{l}- \\
9.26 \\
8\end{array}$ & $* * *$ & -.038 & -.497 & 619 & -1.022 & -5.291 & $* * *$ \\
\hline $\mathrm{H} 3$ & HOTEL<--- TI & .860 & $\begin{array}{l}19.8 \\
64\end{array}$ & $* * *$ & 1.105 & 12.106 & $* * *$ & .764 & 12.736 & $* * *$ \\
\hline H4 & NSS $<---$ TI & .535 & $\begin{array}{l}17.5 \\
86\end{array}$ & $* * *$ & .505 & 7.730 & $* * *$ & .324 & 8.797 & $* * *$ \\
\hline H5 & RE<--- TI & .410 & $\begin{array}{l}9.86 \\
1\end{array}$ & $* * *$ & .836 & 5.924 & $* * *$ & .276 & 2.191 & .028 \\
\hline H6 & RE<--- QTD & .098 & $\begin{array}{l}3.20 \\
0\end{array}$ & .001 & -.295 & -2.711 & .007 & .367 & 2.316 & .021 \\
\hline H7 & QTD<--- HOTEL & .285 & $\begin{array}{l}7.06 \\
0\end{array}$ & $* * *$ & .531 & 5.911 & $* * *$ & .324 & 5.047 & $* * *$ \\
\hline $\mathrm{H} 8$ & QTD<--- NSS & -.392 & $\begin{array}{l}- \\
3.33 \\
8\end{array}$ & $* * *$ & .207 & 2.408 & .016 & .784 & 6.992 & $* * *$ \\
\hline H9 & QTD<--- TI & 1.430 & $\begin{array}{l}14.7 \\
29\end{array}$ & $* * *$ & .973 & 6.188 & $* * *$ & .807 & 15.567 & $* * *$ \\
\hline
\end{tabular}

Note: Std. Estimate standardized estimates, S.E. standard error, C.R. critical ratio

$* p<0.05, \quad * * p<0.01, \quad * * * p<0.001$ 
Table 6. Grouping results of mediation analysis

\begin{tabular}{lllllll}
\hline & Hypotheses\& regression paths & $\begin{array}{l}\text { Specific } \\
\text { indirect } \\
\text { effects }\end{array}$ & $\begin{array}{l}\text { Direct } \\
\text { effect }\end{array}$ & $\begin{array}{l}\text { Total } \\
\text { effect }\end{array}$ & Types of Mediation & Remarks \\
\hline Eastern & H10: RE<---QTD<--- HOTEL & $.028^{* * *}$ & $.318^{* * *}$ & $.346^{* * *}$ & Partial mediation & Supported \\
region & H11: RE<---QTD<--- NSS & $-.039^{* * *}$ & $-.374^{* * *}$ & $-.412^{* * *}$ & Partial mediation & Unsupported \\
& H12: RE<---QTD<--- TI & $.218^{* * *}$ & $.410^{* * *}$ & $.628^{* * *}$ & Partial mediation & Supported \\
\multirow{2}{*}{ Central } & H10: RE<---QTD<--- HOTEL & $-.157^{* * *}$ & $.396^{* * *}$ & $.239 * * *$ & Partial mediation & Unsupported \\
region & H11: RE<---QTD<--- NSS & $-.061^{* * *}$ & $-.038^{\mathrm{NS}}$ & $-.099^{* * *}$ & Full mediation & Unsupported \\
& H12: RE<---QTD<--- TI & $-.072^{* * *}$ & $.836^{* * *}$ & $.763^{* * *}$ & Partial mediation & Unsupported \\
\multirow{2}{*}{ Western } & H10: RE<---QTD<--- HOTEL & $.119^{* * *}$ & $.226^{* * *}$ & $.344^{* * *}$ & Partial mediation & Supported \\
region & H11: RE<---QTD<--- NSS & $.288^{* * *}$ & $-1.022^{* * *}$ & $-.734^{* * *}$ & Partial mediation & Supported \\
& H12: RE<---QTD<--- TI & $.321^{* * *}$ & $.276^{* * *}$ & $.597 * * *$ & Partial mediation & Supported \\
\hline
\end{tabular}

Note: $* p<0.05, * * p<0.01, \quad * * * p<0.001,{ }^{\text {NS }}$ insignificant.

The specific analysis is as follows:

(1)High star-rated hotels have a positive impact on the regional economy of the eastern, central and western regions, with the greatest impact on the central region. The eastern region has attracted more transnational hotel investment with its active tourism and economic and trade exchanges, sound infrastructure and significant location advantages, which has a stimulating effect on economic growth (Dunningand McQueen, 1982; Santos et al., 2016). However, due to the saturation of the market in high star-rated hotels in the eastern region, the room of further improving on star-rated hotel efficiency is getting smaller, and the impact on the regional economy is gradually weakening. Relying on the advantages of tourism resources, the western region has increased the demand for tourism market and enhanced the ability of tourism development to spill over to economic growth. However, the economic development of the western region is relatively backward compared with other regions. The excessive investment in hotel industry is not in line with the development level of its economy and tourism industry, resulting in low occupancy rate of high star-rated hotels, which in turn affects hotel revenue and profit acquisition (Xieet al., 2012).The development level of tourism in the central region is relatively balanced. As the development of the hotel market gradually shifts to the second and third tier cities in the Mainland, the lower investment in hotel construction and relatively high output makes the overall efficiency of high star-rated hotels most conspicuous in central region. Moreover, the degree of industrial concentration of hotel industry in central region is relatively high, and the development of the hotel industry has scale advantages and can bring greater economic benefits (Meiet al., 2011).

(2) The scenic areas has the most prominent direct positive effect on the quality of tourism development and the most prominent indirect positive effect on regional economy intermediated by tourism development quality in western regions. As the main way to promote regional economy in the western region, the tourism industry plays an important role. Therefore, most western provinces regard tourism as the leading industry. As illustrated by Zhao and $\mathrm{Wu}$ (2013), the comprehensive effect of tourism development on economic and social development of the western region will be greater than that of the eastern region, and tourism investment in the western region (such as national-level scenic spots) can obtain higher economic returns.

(3) The transportation infrastructure has the most significant positive effect on the regional economy in the central region. The improvement of the western transport infrastructure does not significantly enhance its links with the developed provinces of the east, while the improvement of the transport infrastructure in the central region has significantly strengthened its economic ties with the east ( $\mathrm{Li}, 2010)$. Therefore, strengthening the transportation infrastructure in the central region can effectively promote economic growth.

In addition, the transportation infrastructure has the most significant indirect positive effect on the regional economy intermediated by tourism development quality in the western region. Compared with the eastern and central regions, the transportation infrastructure of the western region has the highest output elasticity (Guo, 2015). Hence, with the advantage of relatively rich tourism resources and continuous improvement of tourism development quality, the construction of transportation infrastructure in the western region has significant sense on its region economy (Hong, 2015). 


\section{Conclusions}

This paper analyzed the direct and indirect effects of hotels, scenic areas and transportation infrastructure on the regional economy through structural equation modeling (SEM). The following main conclusions were drawn:

(1) From the perspective of full sample analysis, hotels and transportation infrastructure have direct positive effects on regional economy. The quality of tourism development not only has a direct positive effect on the regional economy, but also plays a positivepartial intermediate role between transportation infrastructure and regional economy.

(2) From the perspective of multiple groups of analysis, hotels and transportation infrastructure have the most significant impact on economic development in the central region. The quality of tourism development has played a partial or complete intermediary role in the impact of scenic areas and transportation infrastructure on the regional economy, especially in the western region.

Based on the above conclusions, the following suggestions were proposed:

(1)The scale of star-rated hotel investment should match the level of regional economic development and the stage of tourism development. As the development of the hotel market gradually shifts to the second and third tier cities in the Mainland, more attentions should be paid to the development of the hotel industry in the central region. After all, hotel has the most prominent effect on regional economy in central region.

(2) For scenic areas, especially in western region, the continuous improvement of the quality of tourism development is crucial. Additionally, the One Belt-One Road initiatives is an opportunity for western region to improve its transportation infrastructure to promote its tourism industry and regional economy. Though this paper advances the understanding of the relationships between hotels, scenic areas, transportation infrastructure and regional economy, it still has certain shortcomings. First, it should be noted, as a limitation of this study, that there was not enough data per group to perform subgroup structural equation models. More data are required for structural analyses to be reliable and applicable. Second, subjectivity is unavoidably associated with the selection of socioeconomic variables. All the indicators are chosen based on empirical literature review and data availability. Third, railway and road infrastructure are not the only type of transportation infrastructure. Air transportation (Khan et al., 2017) and high-speed rails (Gao et al., 2019), which play a crucial role and have similar effecting paths on tourism development and regional economy, should be considered in future studies.

\section{Acknowledgement}

The author(s) disclosed receipt of the following financial support for the research, authorship, and/or publication of this article: this research is supported by the National Natural Science Foundation, China (No. 71071093,71471110 and 71301101), and Grant-in-Aid for Scientific Research (C) of Japan Society of Promotion of Science (JSPS): No.15K00357.

\section{References}

Assaf, A. G., Josiassen, A., Agbola, F. W. (2015). Attracting international hotels: locational factors that matter most. Tourism Management, 47(47), 329-340.

Barnabé, W. Zhang, L. (2018). Profit Luenberger and Malmquist-Luenberger indexes for multi-activity decisionmaking units: The case of the star-rated hotel industry in China. Tourism Management 69: 1-11.

Bartlomiej, R., Marcin, S. (2018). Major transport infrastructure investment and regional economic development - An accessibility-based approach. Journal of Transport Geography, 72, 36-49.

Cao, F., Huang, Z., Wu, J., et al. (2012). The Relationship between Tourism Efficiency Measure and Location Accessibility of Chinese National Scenic Areas. Acta Geographica Sinica, 67(12):1686-1697.

Chen, G., Silva, J. D. A. E. (2014). Estimating the Provincial Economic Impacts of High-speed Rail in Spain: An Application of Structural Equation Modeling. Procedia - Social and Behavioral Sciences, 111, 157-165.

Chen, L., Hu, J., Fu, Q., et al. (2014). A study on spatial mismatch between the A-grade tourist attractions and the quality of inbound tourism in Shandong Province. Journal of Central China Normal University (Natural Sciences), 48(05), 755-760.

Chen, X., Huang, F. (2006). A Research on Quantitative Evaluation of Tourism Growth Quality in China. Tourism Tribune, 09:59-63.

Courtney, S., Seyhmus, B., Busser, J. A. (2018). Perceived impacts of medical tourism development on community wellbeing. Tourism Management, 69, 232-245.

Croes, R.Rivera, MA. (2016). Tourism's potential to benefit the poor. Tourism Economics, 23(1): 29-48. 
Dai, S., Xu, H., Pratt, S. (2017). Too much of a good thing? The economic impact of hotel investment in Hainan. Journal of China Tourism Research, 1-20.

Deng, P., Lu, S., Xiao, H. (2013). Evaluation of the relevance measure between ports and regional economy using structural equation modeling. Transport Policy, 27(Complete), 123-133.

Dunning, J. H., McQueen, M. (1982). Multinational corporations in the international hotel industry. Annals of Tourism Research, 9(1), 69-90.

Fan, X., Wei Y. (2016). China with the Core State Economic and Trade Cooperation Under the Silk Road Economic Belt: Based on the SEM Empirical Research Model. On Economic Problems, 04:1-6.

Frank, G., Fine, R., Ricky, Y. (1994). Hong Kong: Sustaining competitive advantage in Asia's hotel industry. Cornell Hotel and Restaurant Administration Quarterly, 35(5), 50-61.

Gao, Y., Su, W., Wang, K. (2019). Does high-speed rail boost tourism growth? New evidence from China. Social Science Electronic Publishing, 72, 220-231.

González-Rodríguez, MR., Jiménez-Caballero,JL.,Martín-Samper, RC., et al. (2018). Revisiting the link between business strategy and performance: evidence from hotels. International Journal of Hospitality Management, 72, 21-31.

Guo, J., Wang, S., Wang, H., et al. (2017). Comprehensive Measure of the Regional Advantages of National Scenic Area. Economic Geography, 37(01):187-195.

Guo, Z. (2015).A Study on Impacts of Transport Infrastructure on Regional Economic Growth in China.Master Thesis, Shandong University, China.

Hew, J. J., Leong, L. Y., Tan, W. H., et al. (2018). Mobile social tourism shopping: a dual-stage analysis of a multimediation model. Tourism Management, 66, 121-139.

Hong, H. (2015). Impact of Transportation Infrastructure on Economic Growth in Western Regions - GMM Estimation Based on Dynamic Panel Data. Finance Economy, (06):58-60.

Hu, Y., Zhu, W. (2015). Spatial Spillover Effects of Transportation Infrastructure: Based on Regional Comparison of the Eastern, Central and Western Regions. Inquiry Into Economic Issues, 01:82-88.

$\mathrm{Hu}$, Y. (2016).The Impact of Transport Infrastructure on the Labor Productivity of Tourism Industry from the Perspective of Spatial Spillover Effects. Master Thesis, Dongbei University of Finance \& Economics, China.

Jeffrey, D., Hubbard, N. J. (1988). Foreign tourism, the hotel industry and regional economic performance. Regional Studies, 22(4), 319-329.

Jiang, X., He, X., Zhang, L., et al. (2017). Multimodal transportation infrastructure investment and regional economic development: a structural equation modeling empirical analysis in China from 1986 to 2011. Transport Policy, 54(Complete), 43-52.

Juan, A., Jimber, R., Francisco, O. A., et al. (2017). Satisfaction in border tourism: An analysis with structural equations. European Research on Management and Business Economics, 23, 103-112.

Juan, I. P., Pablo, J. C., Juan, A. E., (2019). Does environmental sustainability contribute to tourism growth? An analysis at the country level. Journal of Cleaner Production, 213, 309-319.

Kick, E.L., McKinney, L.A. (2014). Global context, national interdependencies, and the ecological footprint: a structural equation analysis. Sociol. Perspect, 57, 256-279.

Lee, T. H., Jan, F. H. (2019). Can community-based tourism contribute to sustainable development? Evidence from residents' perceptions of the sustainability. Tourism Management, 70, 368-380.

Li, D., Bi, H. (2016). Analysis on Spatial Structure of National Forest Park in China. China Population, Resources and Environment, 26(S1):274-277.

Li, H., Liu, Y., Peng, K. (2018). Characterizing the relationship between road infrastructure and local economy using structural equation modeling. Transport Policy, 61, 17-25.

Li, R., Huang, C. (2015). Research on the Impact of Traffic Infrastructure on Regional Tourism Development in China: Based on the Evidence of Threshold Regression Model. Tourism Science, 29(02):1-13+27.

Lin, W. (2013). A Review on the Methods of Evaluating the Economic Value of Tourism Resource in Scenic Area. Economic Geography, 33(09):169-176.

Liu, J., Zhao, L. (2013). Location Layout of Chinese Five-star Hotel: Characteristics and Influencing Factors. Tourism Tribune, 28(08):87-93.

Liu, J. (2017). Research on Space-time Differences of China's Star-rated Hotel Investment and Its Influencing Factors. Statistics \& Decision, 02:113-116.

Li, Y. (2010).The Research of Transportation Infrastructure in Western China and Regional Economic Developmentthe case of highways and railways. Master Thesis, Jilin University, China.

Mei, L., Han, L. (2011). A Study into the Factors Influencing the Spatial Distribution of Star-rated Hotels in China. Economic Geography, 31(09):1580-1584. 
Najaf, P., Thill, J. C., Zhang, W., et al. (2018). City-level urban form and traffic safety: A structural equation modeling analysis of direct and indirect effects. Journal of Transport Geography, 69, 257-270.

Pine, R., Phillips, P. (2005). Performance comparisons of hotels in China. International Journal of Hospitality Management, 24(1), 57-73.

Pradhan, R. P., Bagchi, T. P. (2013). Effect of transportation infrastructure on economic growth in India: the VECM approach. Research in Transportation Economics, 38(1), 139-148.

Qu, W. (2004).Research on the Core Competitiveness of Tourism in National Key Scenic Spots. Master Thesis, Huaqiao University, China.

Rehman Khan, S. A., Qianli, D., Songbo, W., et al. (2017). Travel and tourism competitiveness index: The impact of air transportation, railways transportation, travel and transport services on international inbound and outbound tourism. Journal of Air Transport Management, 58, 125-134.

Santos, M., Brochado, A., Esperança, José. (2016). Foreign direct investment patterns of global hotel chains. Journal of Business Research, 69(11), 5235-5240.

Sarmento, M., Simões, Cláudia. (2018). The evolving role of trade fairs in business: A systematic literature review and a research agenda. Industrial Marketing Management, 73, 154-170.

Shao, S., Tian, Z., \& Yang, L. (2017). High-speed rail and urban service industry agglomeration: Evidence from China's Yangtze River Delta region. Journal of Transport Geography, 64, 174-183.

Shi, Ji, Wang, Li. (2016). Impacts of star-rated hotel expansion on inbound tourism development: evidence from China. Applied Economics, 48(32), 1-16.

Song, W. (2016).Study on the Temporal and Spatial Distribution Regularity and Influence Mechanism of High Starlevel Hotels in Shanghai. Master Thesis, Shanghai Normal University, China.

Strauss, J., Li, H., Hu, S., et al. (2018). Do high-speed railways lead to urban economic growth in China? A panel data study of China's cities. The Quarterly Review of Economics and Finance, 69, 70-89.

Sun, L. (2005). The Principle and Operation of Structural Equation Modeling (SEM). Journal of Ningbo University (Educational Science), 27(02), 31-34+43.

Tang, C. F., Abosedra, S. (2014). The impacts of tourism, energy consumption and political instability on economic growth in the mena countries. Energy Policy, 68, 458-464.

Wang, S., Guo, J. (2016). Spatial measure of traffic accessibility and marketpotential of the National Scenic Areas. Geographical Research, 35(9), 1714-1726.

Xie, C., Wang, E., Zhu, Y. (2012). A Study on Efficiency Evaluations of China's Five-Star Hotels: Based on SuperEfficiency DEA Model. Tourism Science, 26(01):60-71.

Yadegaridehkordi, E., Nilashi, M., Nasir, M., et al. (2018). Predicting determinants of hotel success and development using Structural Equation Modelling (SEM)-ANFIS method. Tourism Management 66: 364-386.

Yang, M. (2013).The Study on Space-time Disparity of Resources Structure and Tourists Structure-A Case Study of Chinese National Park.Master Thesis, Northwest Normal University, China.

You, H. (2017). Agricultural landscape dynamics in response to economic transition: comparisons between different spatial planning zones in Ningbo region, China. Land Use Policy, 61, 316-328.

Zhang, A., Zhong, L., Xu, Y., et al. (2015). Characteristics and Spatial Difference of Provincial Tourism Development Quality in China. Scientia Geographica Sinica, 35(03):283-292.

Zhang, X., Zhao, X. (2018). The Impact of Transport Infrastructure and Its Spillover on Tourism: Based on the Data of Hotel, Travel Agencies and Scenic Spot. Business Management Journal, 40(04):118-133.

Zhao, L., Fang, C., Mao, C. (2018). Tourism and Poverty Reduction: An Empirical Evidence from China. Tourism Tribune, 33(05):13-25.

Zhao, Y.,Wu, F. (2013). The Coordination Mechanism and the Basic Route of Regional Economic Disparity under the Influence of Tourism. On Economic Problems, (09):4-10+105.

Zhe, O., Wei, W., \& Chi, C. G. (2019). Environment management in the hotel industry: does institutional environment matter? International Journal of Hospitality Management, 77, 353-364.

Zhou, G., Peng, P., Tang, C., et al. (2002). The Measurement and Evaluation on the Imbalance of Regional Economic Development of China in 1990s. China Soft Science, (10):88-93.

Zhu, H., Chen, X. (2008). Space Distribution Structure of A-grade Scenic Spot in China. Scientia Geographica Sinica, (05):607-615.

Zuo, B., Gursoy, D., Wall, G. (2017). Residents' support for red tourism in China: the moderating effect of central government. Annals of Tourism Research, 64, 51-63. 